\title{
Correction of involutional skin changes using microfocused ultrasound combined with PRP-therapy
}

\author{
Zhanna Yu. Yusova ${ }^{1}$, Tatiana V. Stepanova², Elena L. Baranova³, Diana V. Demidion ${ }^{3}$
}

\begin{abstract}
Introduction: In aesthetic medicine, the use of hardware technologies occupies an important place. Hardware action on skin includes microfocused ultrasound, radiowave, light and laser methods. The ultimate task of each method consists in improving the condition of skin and its rejuvenation. However, to enhance the clinical efficiency, combined actions have been suggested recently.

Objective: To compare the effect of microfocused ultrasound as monotherapy and the combined application thereof with autologous blood cell factors.

Methods: For assessing efficiency of the procedures undertaken, the data of ultrasonic scanning of skin were studied, photo documentation was performed, and adapted dermatological indices were used: the dermatological status index (DLQI) and WAM index (wellbeing, activity, mood).

Results: According to the research results, ultrasonic skin scanning data were obtained which gave evidence about a more pronounced clinical effect in patients having received the combined application of microfocused ultrasound with autologous blood cell factors. The improvement of qualitative characteristics of skin in the form of a thicker dermal stratum and improved dermal coefficient was observed both in the patients having received monotherapy by microfocused ultrasound and in the group where patients underwent its combined application with autologous blood cell factors. However, the improvement of clinical effect was significantly higher in patients having received the combined application as compared to the microfocused ultrasound monotherapy group, which confirms the synergism of the hardware method and the use of factors of autologous blood cells (thrombocytes). Such manifestations as a significant increase of thickness of epidermis in 6 months in patients having received the microfocused ultrasound monotherapy gives an indirect evidence about the presence of compensated dehydration in reparative processes; this is a norm, but it curbs performance of other stimulations. Photo documentation and the analysis of dermatological indices also correlated with the data of US examination of skin. The pronounced clinical efficiency in the use of combined treatment confirms the synergism of the said two methods aimed at improving the quality of skin.

Conclusion: The use of autologous blood cell factors significantly improves clinical results and allows employing other stimulation procedures in the integrated correction (laser technologies, radiofrequency methods) after microfocused ultrasound within the periods of up to 6 months after treatment.
\end{abstract}

Keywords: microfocused ultrasound, ultrasonic scanning of skin, involutional changes of skin, factors of autologous blood cells, aesthetic medicine

\section{INTRODUCTION}

Hardware methods in aesthetic medicine are represented by a broad range of physical factors used (1-5). State-ofthe-art technologies allow conducting procedures at the minimum injury rate, no need for rehabilitation, and a good tolerability $(1,2,5-14)$. As new technologies are used, there arises the necessity to differentiate their administration and to combine them with other methods for enhancing clinical efficiency of the procedures $(3,14-17)$. In particular, when microfocused ultrasound is used, precise areas of spatially-focused chromophore-independent thermal $\left(60-70{ }^{\circ} \mathrm{C}\right)$ coagulative damage are created. As a result of the action, collagen fibers degrade, and this destroyed collagen stimulates neocollagenesis by the "feedback" principle, increasing the thickness of derma and the collagen content in its reticular stratum further on, without affecting intermediate tissues or underlying skin meanwhile (1,2,5-14). Microfocused ultrasound suits best for patients having a light and moderate extent of laxity of skin and soft tissues, because the clinical response to microfocused ultrasound correction partially depends on the synthesis of collagen and the extent of so-

\footnotetext{
1 Administrative Department of the President of the Russian Federation, Federal Sate Budgetary Institution of the Additional Professional Education "Central State Medical Academy", Moscow, Russia.

2 Center for Aesthetic Medicine "Astrea", Cheboksary, Russia

3 Premium Aesthetics Academy of Cosmetology, Moscow, Russia

Correspondence: Tatiana V. Stepanova

Center for Aesthetic Medicine "Astrea", Cheboksary, Russia.

E-mail: t.stepanova76@mail.ru

Received: 21 Aug 2019, Accepted: 27 Nov 2019

(C) 2019 by the authors; licensee Modestum Ltd., UK. This article is an open access article distributed under the terms and conditions of the Creative Commons Attribution License (http://creativecommons.org/licenses/by/4.0/).
} 
called wound healing response $(1,15)$. Published works list data on the results of patients' satisfaction after the microfocused ultrasound procedure conducted. In various published works, the data differ $(2,4,8-11,14,15,18,19)$. According to the data of studies of patients' satisfaction with microfocused ultrasound procedures, the data are varied, but they give evidence about high efficiency. So, improvements were observed in $81.3 \%$ of patients according to PSQ scale. 180 days later, $84.4 \%$ of patients reported the absence of improvements. Meanwhile, $62.5 \%$ of 45 were satisfied or extremely satisfied in 90 days after treatment, and 60\% - in 180 days after treatment (10).

As new technological opportunities aimed at renovation of skin structures are created, there arise questions about regenerative potential for a higher efficiency and satisfaction of patients. As of today, one of the leading trends for enhancing the regenerative potential is the use of autologous blood cell factors. The study of platelet-derived growth factors and their effect on restoration of derma has been described in many published works $(20-24,25-27)$. The clinical effect is first of all due to the presence of growth factors, the content of microelements, cytokines, and other structures involved in the regeneration triggering cascade $(21,24,25,27)$. Given a relatively high yet insufficient percentage of clinical improvements after microfocused ultrasound with neocollagenogenesis launched, it becomes essential to enhance the regenerative potential of skin to obtain higher clinical results. In this research, the authors used autologous blood cell factors combined with the use of microfocused ultrasound for solving this problem.

\section{LITERATURE REVIEW}

The objective of all equipment for non-invasive skin lifting, the microfocused ultrasound one included, consists in heating the specific target tissue by means of a source of energy (focused ultrasound), which at the same time allows avoiding the accompanying damage of the surrounding tissues (1,2,5-14). The target tissue is a network of collagencontaining tissues, including the reticular stratum of derma, fibrous septa in subcutaneous fat, and fascial strata. The objective of the newest technologies consists in a safe action on all these tissues which are involved into the skin ageing process.

The use of microfocused ultrasound for treatment purposes has been practiced for over 70 years already, but currently, one can speak about a kind of renaissance of this treatment method.

The advantage of the focused ultrasound procedure consists in the fact that within one procedure, lifting of soft tissues can be achieved by working at different levels of soft tissues of face, while also improving qualitative characteristics of skin $(1,3,11)$.

Transcutaneous microfocused ultrasound energy pulses of a short duration of 25-50 msec within the $\mathrm{MHz}$ frequency range (to level out any cavitation processes emerging) create precise areas of spatially-focused, chromophoreindependent thermal $\left(60-70{ }^{\circ} \mathrm{C}\right)$ coagulative damage, sized less than $1.0 \mathrm{~mm}^{3}$. As a result of this quick spot heating, collagen fibers degrade, and this destroyed collagen stimulates neocollagenesis by the "feedback" principle, increasing the thickness of derma and the collagen content in its reticular stratum further on, (1,2,5-14).

In response to the thermal stress, in subletal heating areas around the coagulation spots, heat-shock proteins (HSP47, HSP-70, HSP-90) are released which prevent the development of apoptosis of fibroblasts and induce the synthesis of transforming growth factor TGF- $\beta$. This growth factor is the key element in the wound healing process as well as in the formation of connective tissue and collagen fibers in particular (13).

After the acute thermal shortening of collagen molecule, the restoration process takes up around 1 month. In 3 months after the treatment, epidermal hyperplasia and thickening with epidermal ridges developing are observed. The quantity of newly synthesized collagen increases significantly during 6 months after the treatment. However, there are data in some published works that after the microfocused ultrasound action procedure, the remodeling process in skin goes on in three months. Studies have shown that in the process of physiological neocollagenogenesis, the remodeling stage during which type III collagen is gradually substituted with mature type I collagen can take up to one year $(13,16)$.

As one procedure cannot correct the entire cascade of involutional skin changes, so the diversity of tasks is addressed by the integrated approach or by a combination of several methods: injection ones and hardware ones $(3,14-17)$. As of today, there is not enough data about the combined use of microfocused ultrasound with other cosmetic procedures (14).

There are published works conducting a retrospective analysis of the data of patients who underwent procedures using incobotuloboxin A, dermal fillers based on hyaluronic acid with cohesive polydensified matrix (CPDM) and calcium hydroxyapatite ( $\mathrm{CaHA})$ within 6 months before / after microfocused ultrasound was performed on the same or another anatomical area $(14,15,17)$. 
The same work cites the results of studying the combined treatment with microfocused ultrasound and injection of diluted calcium hydroxyapatite into the neck and décolleté area in 90 days (14-15).

In another retrospective study, the authors assessed the combined use of microfocused ultrasound with intensive pulse light and poly-L-lactate dermal filler. The results of this research have shown that all the three procedures can be conducted safely within one period of time, and the safety profile of such a combination does not differ from that of each of the procedures taken individually (14).

The combination of collagen-stimulating injectable preparations with a collagen-stimulating hardware procedure can yield a synergetic effect $(3,14-17)$.

Tissues exposed to an intensive thermal action (similar to focused ultrasound treatment) are known to have a higher need of aminoacids which are capable to ensure quick reparation and, therefore, restoration, and they also need detoxication. A positive experience of combining microfocused ultrasound with the use of aminoacidic complexes by ingestion is available.

These studies emphasize the importance and relevance of the problem of enhancing the efficiency of using microfocused ultrasound.

One of the promising lines for improving regeneration is the use of factors of autologous blood cells.

In 1995, the Endoret technique was patented. Platelet-rich plasma found use in clinical practice, dentistry, traumatology, surgery, sports medicine, and, particularly, in cosmetology, for the purpose of improving tissue regeneration, as a means for endogenic stimulation thereof $(20,25,27)$.

The advantage of this method consists in the fact that this biomaterial can be easily obtained from blood by biotechnological means, and it can be used in various situations to aid physiological wound healing and the faster regeneration of tissues $(20,25,27)$.

Biologically active regulators that are available in PRGF (Plasma Rich in Growth Factors) stimulate tissue regeneration and activate numerous biological processes, including recruiting, proliferation, migration of cells, cellular differentiation, formation of new vessels, and extracellular matrix deposition $(20,23,25)$.

The autologous approach - the use of platelet factors of the patient's own plasma - is not only useful for antifibrotic wound healing, but it also ensures the efficient protection against photo-oxidative stress caused by sunlight regardless of the patient's age (24). Plasma contains thrombocytes at the optimum concentration, and after activation, they free up a mixture of autologous growth factors and some other bioactive molecules from the plasma fraction. Growth factors and cytokines freed up from thrombocytes are considered to have an essential normalizing influence on biological processes underlying regeneration and reparation of tissues: proliferation of cells and their migration, inflammation, angiogenesis, as well as the appropriate synthesis of intercellular matrix components $(20,23,24,27)$.

With regard to this, autoplasma has no toxic and thrombogenic action. Growth factors contained in thrombocytes promote proliferation and angiogenesis, but they do not lead to cancerogenesis and hyperplasia (20).

After treatment with PRGF (Plasma Rich in Growth Factors), the statistically significant increase of thickness of epidermis and papillar derma was registered. The higher thickness of skin was observed in all patients regardless of their age or the gravity of skin photo-damage which they had initially (23).

In punch biopsy test conducted before and 6 months after the course of PRGF (Plasma Rich in Growth Factors), marked improvements of collagen and elastinic networks were found, as well as newly formed vessels (VEGF-mediated angiogenesis) (20,25).

Injection of plasma activated with growth factors into derma stimulates regenerative processes and considerably reduces the inflammation stage after high-energy procedures. This is why this method is indicated after laser procedures (both ablation and non-ablation ones), IPL-treatment, as well as after treatment with high-intensity microfocused ultrasound to ensure the maximum response of dermal structures to the powerful energy action while also not causing post-inflammatory hyperpigmentation $(25,27)$.

\section{RESEARCH METHODOLOGY}

The objective of the work: studying and comparing clinical efficiency of the combined use of microfocused ultrasound with autologous blood cell factors and microfocused ultrasound as monotherapy. 


\section{Distribution of the patients}

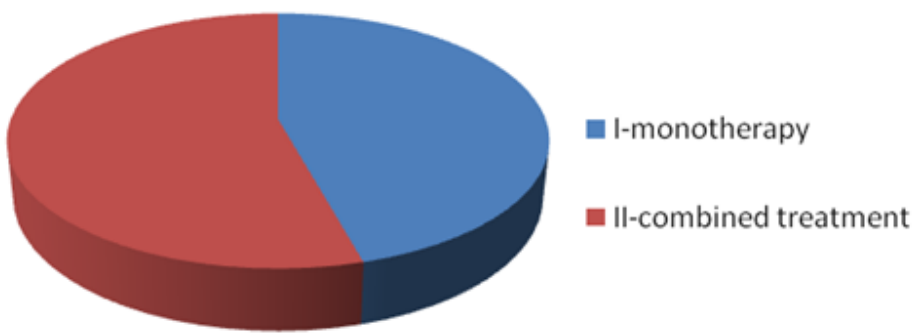

Figure 1: Distribution of the patients into groups. Source: authors

\section{MATERIAL AND METHODS}

The research was conducted from November 2018 through July 2019 within the scientific work of the department of dermatovenereology and cosmetology of FSBI FPE "Central State Medical Academy" at the Department for Presidential Affairs of the Russian Federation, Moscow. Under the authors' observation, there were 35 patients of the Astrea clinics (Cheboksary) having manifestations of involutional skin changes aged 40 to 50 . Among them, there were 2 men (5,71\%) and 33 women (94.29\%). All patients were subdivided into 2 groups according to the treatment indicated: group $1-16$ patients who underwent procedures with microfocused ultrasound used as monotherapy, group $2-19$ patients receiving the combined therapy with microfocused ultrasound and autologous blood cells which were introduced by injections. Distribution of the patients according to groups is shown in Figure 1.

Exclusion criteria: skin diseases in the active stage, herpetic and other infectious processes on skin in the exacerbation stage, general infectious diseases, chronic somatic diseases in the exacerbation stage, mental conditions, administration of antidepressant medications or preparations affecting the central nervous system, epilepsy, propensity to form keloid scars, oncological diseases, administration of photosensitizers, pregnancy, lactation, blood coagulation pathologies (thrombocytopenia, hemodynamic instability, antiphospholipid syndrome, anticoagulant therapy), pronounced immunodepression, diseases of the connective tissue (Ehlers-Danlos disease, sclerodermia).

\section{Aesthetic Correction Methods}

For correction of involutional skin changes, the method of linear successive multiple microfocused ultrasound wave $(\mathrm{MU})$ action was selected. The procedure was conducted on skin over medium viscosity gel for ultrasonic examinations, using transducer DS $7-3.0$ at the energy of $0.45 \mathrm{~mJ}$ ( $7 \mathrm{MHz}$ frequency). The quantity of lines (runs) for the area of the lower third of the face and the submandibular space amounted to 310 lines.

The treatment with autologous blood cells was performed with preparations Endoret PRGF (certificate of registration No. RZN 2014/1995) after preliminary topical anesthesia (the EMLA preparation) by microdoses injection method (up to 0.1-0.3 $\mathrm{ml}$ ) at the distance of $0,8-1,5 \mathrm{~cm}$ between intra- and subdermal injections. The consumption of Endoret PRGF per procedure was from 4 to $8 \mathrm{ml}$ of PRGF.

For objectifying the assessment of efficiency of the treatment conducted, adapted dermatological indices were used: the dermatological status index (DLQI), and the WAM index (wellbeing, activity, mood). The dermatological index of the quality of life, DLQI (Dermatology Life Quality Index, Finlay, 1994), is a standardized questionnaire form for patients to assess their functioning independently, with social, daily life and interpersonal aspects considered. The questionnaire form contains 10 questions, each of which is assessed according to a three-point system and depends on the extent. The results were nullified, if there were no answers to 2 and more questions in the form. When calculating the index, all values were added up. For DLQI, the minimum value is 0 points, and the maximum value equals 30 points. When the values are high, a negative effect of the current condition of skin on the quality of life is registered. The test has been adapted for patients having involutional skin signs; their condition does not belong to dermatological nosology, so high values are not provided for. The WAM index, "Wellbeing. Activity. Mood," was used in this research to identify the mental and emotional condition of patients. Each constituent is assessed by patients according to a 5-point scale. The data were interpreted both for individual parameters and for the average values.

Special examinations were also conducted - ultrasonic sonography for finding out echostructural particularities of epidermis and derma (DUB Skinscanner 22-75, TPM, Germany, $75 \mathrm{MHz}$ transducer) over 3 points: 2 symmetrical points 


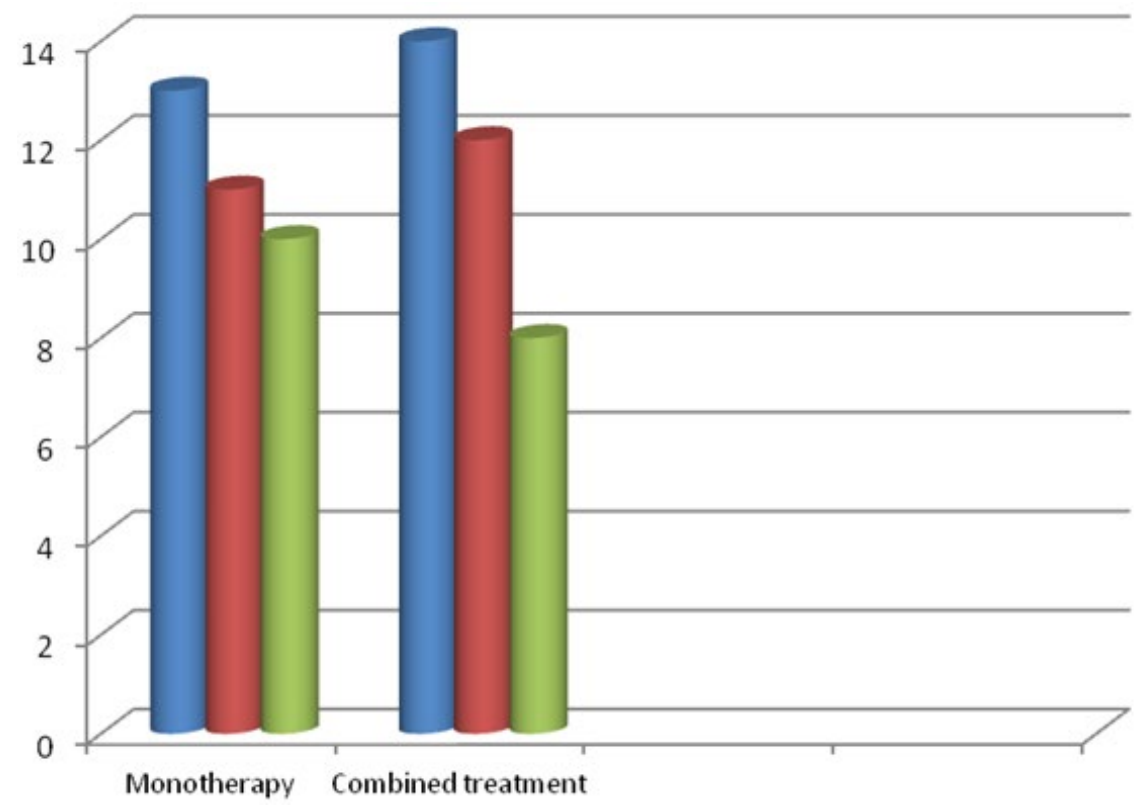

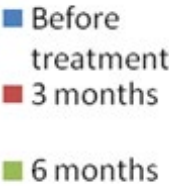

6 months

Figure 2: DLQI figures after the use of monotherapy and combined method in patients having involutional skin changes ( ${ }^{*}$ along ordinate axis, there are DLQI median values, at $p<0.01$ according to Mann-Whitney test, comparison with initial figures). Source: authors

Table 1: WAM index parameters in patients having involutional skin changes before and after treatment ( $\pm \pm m$, points)

\begin{tabular}{ccccc}
\hline \multirow{2}{*}{ Parameters } & \multicolumn{2}{c}{$\begin{array}{c}\text { Monotherapy } \\
\text { Group 1 }\end{array}$} & \multicolumn{2}{c}{$\begin{array}{c}\text { Combined treatment } \\
\text { Group 2 }\end{array}$} \\
\cline { 2 - 5 } & Before treatment & In 6 months & Before treatment & In 6 months \\
\hline Wellbeing & $3.86 \pm 0.08$ & $4.31 \pm 0.08^{*}$ & $3.73 \pm 0.06$ & $4.51 \pm 0.05^{*}$ \\
\hline Activity & $4.02 \pm 0.06$ & $4.08 \pm 0.05^{*}$ & $3.98 \pm 0.05$ & $4.61 \pm 0.08^{*}$ \\
\hline Mood & $3.24 \pm 0.10$ & $4.35 \pm 0.05^{*}$ & $3.15 \pm 0.06$ & $4.98 \pm 0.07^{*}$ \\
\hline Total value of the WAM index & $3.74 \pm 0.12$ & $4.47 \pm 0.09^{\star}$ & $3.65 \pm 0.08$ & $4.52 \pm 0.07^{\star}$ \\
\hline
\end{tabular}

Note: ${ }^{*}-p<0.01-$ the validity level of distinctions before and after the treatment. Source: authors

at the middle of the "mouth commissure - tragus" distance and 1 point at the middle of the distance from the middle of chin to the upper edge of thyroid cartilage.

The procedure was conducted as a single test with subsequent clinical observation in 6 months. Thus, the condition of skin, DLQI and WAM were assessed at the first visit - before the procedure - and at the second visit - 6 months after the procedure.

\section{RESULTS AND DISCUSSION}

Before undergoing the procedures of aesthetic correction, all patients under observation had a high integral figure of DLQI (dermatology life quality index), which is due to the patients' underestimation of their appearance and, consequently, its negative effect on their functioning in daily life. When analyzing the same parameters in 3 and 6 months, a trend for improving this figure was registered in all patients. However, in the group receiving the combined treatment, the DLQI figure differed - a more pronounced reduction of it was recorded (Figure 2), which indirectly confirms high clinical efficiency of the conducted treatment.

So, in group 1, initial values were $13.9[\mathrm{Q} 1=13.1 ; \mathrm{Q} 3=14.3]$ points. 6 months after the procedure of linear successive multiple microfocused ultrasound wave as monotherapy was conducted, their DLQI figure improved by $23.8 \%-10.2$ $[Q 1=9.9 ; \mathrm{Q} 3=10.5]$ points $(p<0.01$, comparison with the initial one). In the group of patients who underwent the combined treatment with linear successive multiple microfocused ultrasound wave and autologous blood cells, the initial index values were $14.3[\mathrm{Q} 1=14.1 ; \mathrm{Q} 3=14.5]$ points, and 6 months after the beginning of therapy, the DLQI figure improved by $57.1 \%$, equaling $8.2[Q 1=7.8 ; Q 3=8.6]$ points ( $p<0.01$, comparison with the initial one).

When assessing the WAM index dynamics after the use of the combined method, there was a clear positive dynamics of all constituents of the index, their average values included (general WAM index), as compared to the monotherapy group. In particular, the total WAM index has shown a $17.3 \%$ increase in group 1, while it has gone $18.3 \%$ up in group 2 (Table 1). 
Table 2: Data of the US scanning before and after the therapy $(M \pm m)$

\begin{tabular}{lcccc}
\hline \multirow{2}{*}{ Parameter } & \multicolumn{2}{c}{ Group 1 } & \multicolumn{2}{c}{ Group 2 } \\
\cline { 2 - 5 } & Before correction & After correction & Before correction & After correction \\
\hline Thickness of epidermis, $\mu \mathrm{m}$ & $96.6 \pm 0.168$ & $107.6 \pm 0.236^{*}$ & $97 \pm 0.452$ & $101.5 \pm 0.221^{*}$ \\
\hline Thickness of derma, $\mu \mathrm{m}$ & $1338.9 \pm 0.376$ & $1490.7 \pm 0.471^{*}$ & $1328.2 \pm 0.367$ & $1586.4 \pm 0.358^{\star}$ \\
\hline Coefficient of ultrasonic density of derma, \% & $1.76 \pm 0.157$ & $1.39 \pm 0.329^{\star}$ & $1.81 \pm 0.185$ & $1.34 \pm 0.128^{\star}$ \\
\hline
\end{tabular}

Note: ${ }^{*} p<0.01$, comparison with parameters before treatment. Source: authors
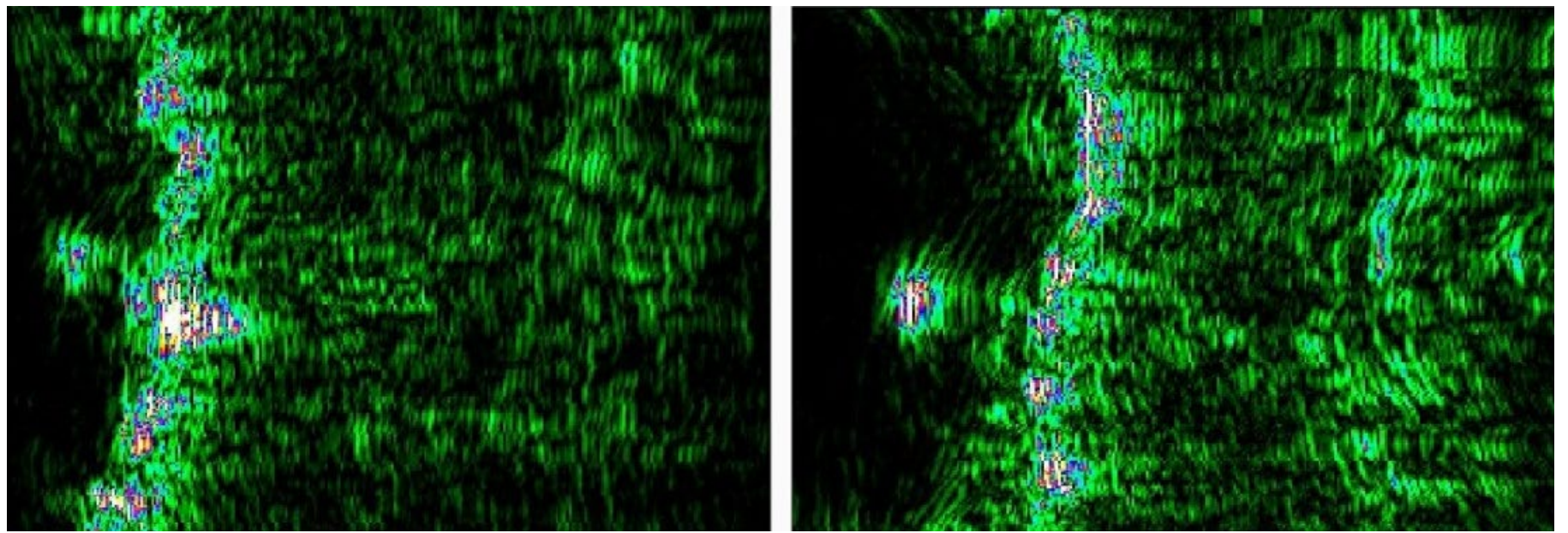

Figure 3: US scanning of skin: $a$ - before, $b$ - after treatment in group 1. Source: authors

The integrated assessment of dynamics of figures of the DLQI and WAM indices gives evidence about a marked positive influence of the combined technique on the patients' daily functioning, their mental and emotional condition, which determines the ultimate objective of correction of involutional changes of the face skin.

To find out initial changes in the skin structure, as well as the dynamics of main parameters after administration of the treatment, ultrasonic scanning was performed. Under dystrophic processes (the processes of ageing) in skin, changes of the structure of derma are observed that are associated with disorders on the part of microcirculation (congestive phenomena, vascular distention of the superficial papillary plexus of derma) and with reduction of functional activity of fibroblasts leading to the change of fibrous structures and intercellular matrix composition (lower synthesis of fibers, hyaluronic acid, etc.). In the dynamic ultrasonic observation of patients, positive dynamics can be seen well both in the case of using monotherapy (MU) and in the case of its combined use with autologous blood cells. This was expressed in the higher thickness of derma and more even distribution of structural components (the ultrasonic density) in the deep and superficial strata (Table 2).

In group 1, there was less dynamics observed, with a minor increase of thickness of derma - at $+10,46 \%$. Meanwhile, there was a significant shift of the US density distribution coefficient toward the normal value limits (with the norm ranging from 0.75 to 1.50 conventional units) from 1.76 to 1.39. In patients of the second group, the derma thickness increment amounted to $+19.03 \%$ (Figure 3 ). Such changes speak about a more intensive action on the synthetic activity of fibroblasts under the combined approach - a combination of local therapy (microfocused ultrasound) with regional action (factors of autologous blood cells). This combination allows not only directly stimulating the functional activity of fibroblasts at the moment of treatment, but also restoring the systemic functioning of derma in the post-procedural period owing to normalization of microcirculation, restoration of the normal trophicity of derma and surrounding tissues.

Ultrasonic scanning of skin of group 1 patients shows a minor increment of thickness of derma with a better ultrasonic density coefficient and a significant increase of thickness of epidermis.

In ultrasonic scanning of skin of the patients of group 2, an increase of thickness of derma and a better ultrasonic density coefficient are observed; meanwhile, the thickness of epidermis remains almost unchanged (Figure 4). Photo documentation, too, reflects the trend of more pronounced clinical results in the group having received the combined treatment protocol. 

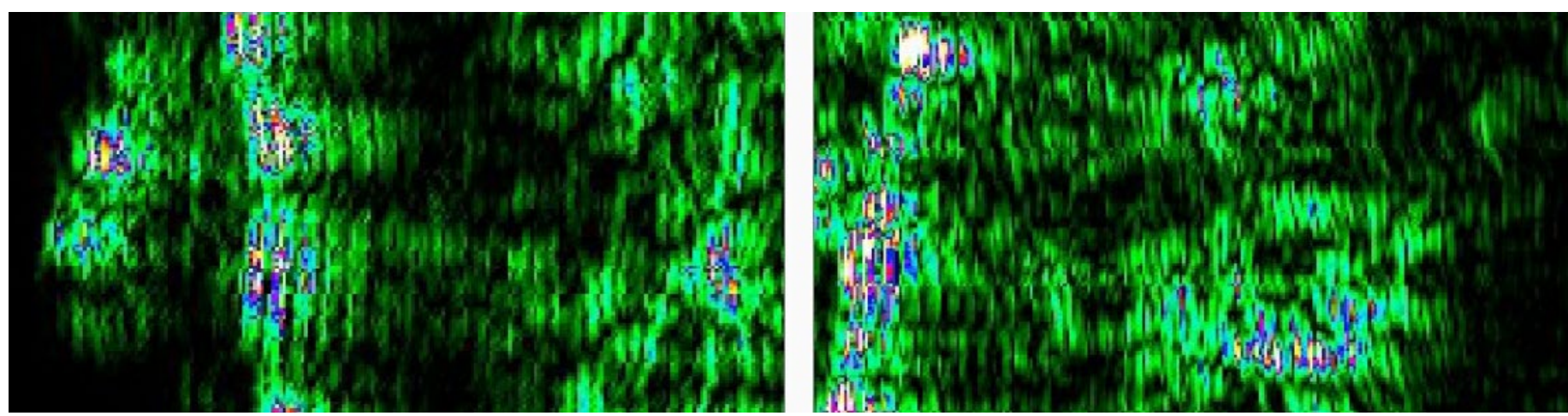

Figure 4: US scanning of skin: $a$ - before, $b$ - after treatment in group 2. Source: authors

\section{CONCLUSION}

When conducting monotherapy with the help of focused ultrasound, a high clinical efficiency is identified in patients in observation up to 6 months, the US confirms a positive effect on skin; however, the significant increase of thickness of epidermis in this group is an indirect sign of insufficient regenerative potential of skin. This can be a contraindication for other stimulation aesthetic procedures performed within 6 months. In the group having received the combined treatment, clinical results were higher, and the thickness of epidermis was not changed significantly, which gives indirect evidence about a more favorable regenerative background of skin.

Thus, the data of the comparative study of clinical efficiency shown by the combined use of microfocused ultrasound with autologous blood cell factors and by microfocused ultrasound monotherapy confirm pronounced clinical results in all groups. However, significantly better results were identified in the combined method cases. Pronounced clinical efficiency in the group having undergone combined treatment gives evidence about the higher synthetic activity of fibroblasts owing to thrombocyte factors. The obtained data suggest including methods aimed at enhancing the regenerative potential of derma and limiting other aggressive stimulating procedures for 6 months (laser resurfacing, radiofrequency actions) after the use of microfocused ultrasound.

\section{REFERENCES}

1. Fabi SG. Noninvasive skin tightening: focus on new ultrasound techniques. Clinical, Cosmetic and Investigational Dermatology, 2015;8:47-52. https://doi.org/10.2147/CCID.S69118 PMid:25709486 PMCid:PMC4327394

2. Fabi SG, Massaki A, Eimpunth S, Pogoda J, Goldman MP. Evaluation of microfocused ultrasound with vizualization for lifting, tightening and wrinkle reduction of the decolletage. Journal of the American Academy of Dermatology, 2013;69(6):965-71. https://doi.org/10.1016/j.jaad.2013.06.045 PMid:24054759

3. Fabi SG, Pavicic T, Braz A, Green JB, Seo K, van Loghem JA. Combined aesthetic interventions for prevention of facial ageing, and restoration and beautification of face and body. Journal Clinical, Cosmetic and Investigational Dermatology, 2017;10:423-9. https://doi.org/10.2147/CCID.S144282 PMid:29133982 PMCid:PMC5669783

4. MacGregor JL, Tanzi EL. Microfocused ultrasound for skin lifting. Seminars in Cutaneous Medicine and Surgery, 2013;32(1):18-25.

5. Hye Suh D, Hwee Choi J, Jun Lee S, Ki-Heon J, Yong Song K, Kyung Shin M. Comparative histometric analysis of the effects of high-intensity focused ultrasound and radiofrequencies on skin. Journal of Cosmetic and Laser Therapy, 2015;17(5):230-6. https://doi.org/10.3109/14764172.2015.1022189 PMid:25723905

6. Phenix CP, Togtema M, Pichardo S, Zehbe I, Curiel L. High intensity focused ultrasound technology, its scope and applications in therapy and drug delivery. Journal of Pharmacy and Pharmaceutical Sciences, 2014;17(1):136-53. https://doi.org/10.18433/J3ZP5F PMid:24735765

7. Hitchcock TM, Dobke MK. Review of the safety profile for microfocused ultrasound with visualization. Journal of Cosmetic Dermatology, 2014;13(4):329-35. https://doi.org/10.1111/jocd.12111 PMid:25399626

8. Fabi SG. Microfocused ultrasound with visualization for skin tightening and lifting: my experience and a review of the literature. Dermatologic Surgery, 2014;12:164-7. https://doi.org/10.1097/DSS.0000000000000233 PMid:25417569

9. MacGregor JL, Tanzi EL. Microfocused ultrasound for skin tightening. Seminars in Cutaneous Medicine and Surgery, 2013;32(1):18-25. 
10. Fabi SG, Goldman MP. Retrospective evaluation of the use of microfocused ultrasound for lifting and strengthening the skin of the face and neck. Dermatologic Surgery, 2014;40(5):569-75. https://doi.org/10.1111/dsu.12471 PMid:24689931

11. Oni G, Hoxworth R, Teotia S, Brown S, Kenkel JM. Evaluation of a microfocused ultrasound system for improving skin laxity and tightening in the lower face. Aesthetic Surgery Journal, 2014;34(7):1099-110. https://doi.org/10.1177/1090820X14541956 PMid:24990884

12. Friedmann DP, Bourgeois GP, Chan HL, Zedlitz AC, Butterwick KJ. Complications from microfocused transcutaneous ultrasound: case series and review of the literature. Lasers in Surgery and Medicine, 2018;50(1):13-9. https://doi.org/10.1002//sm.22768 PMid:29154457

13. Gutowski KA. Microfocused ultrasound for skin tightening. Clinics in Plastic Surgery, 2016;43(3):577-82. https://doi.org/10.1016/j.cps.2016.03.012 PMid:27363772

14. Fabi SG, Goldman MP, Mills DC, Werslcher WP, Green JB, Kaufman J, Weiss RA, Hornfeldt CS. Combining Microfocused Ultrasound With Botulinum Toxin and Temporary and Semi-Permanent Dermal Fillers: Safety and Current Use. Dermatologic Surgery, 2016;2:168-76. https://doi.org/10.1097/DSS.0000000000000751 PMid:27128245

15. Casabona G, Nogueira Teixeira D. Microfocused ultrasound in combination with diluted calcium hydroxylapatite for improving skin laxity and the appearance of lines in the neck and decolletage. Journal of Cosmetic Dermatology, 2018;17(1):66-72. https://doi.org/10.1111/jocd.12475 PMid:29285863

16. Casabona G, Pereira G. Microfocused ultrasound with visualization and calcium hydroxyapatite for improving skin laxity and cellulite appearance. Plastic and Reconstructive Surgery - Global Open, 2017;5(7):e1388. https://doi.org/10.1097/GOX.0000000000001388 PMid:28831339 PMCid:PMC5548562

17. Casabona G. Combined use of microfocused ultrasound and a calcium hydroxylapatite dermal filler for treating atrophic acne scars: A pilot study. Journal of Cosmetic and Laser Therapy, 2018;20(5):301-6. https://doi.org/10.1080/14764172.2017.1406606 PMid:29400587

18. Fabi SG, GoLdman MP, Dayan SH, Gold MH, Kilmer SL, Hornfeldt CS. A prospective multicenter pilot study of the safety and efficacy of microfocused ultrasound with visualization for improving lines and wrinkles of the decolletage. Dermatologic Surgery, 2015;41(3):327-35. https://doi.org/10.1097/DSS.0000000000000322 PMid:25705947

19. Jung Lee $H$, Real Lee K, Yang Park J, Soo Yoon M, Eun Lee S. Efficacy and safety of intense focused ultrasound in the treatment of enlarged facial pores in Asian skin. Journal of Dermatological Treatment, 2015;26(1):73-7. https://doi.org/10.3109/09546634.2013.868862 PMid:24512647

20. Navarro MR, Asin M, Martinez AM, Molina C, Navarro V, Pino A, Orive G, Anitua E. Plasma rich in growth factors (PRGF) for the treatment of androgenetic alopecia. European Journal of Plastic Surgery, 2015;38(6):437-42. https://doi.org/10.1007/s00238-015-1116-z

21. Anitua $E$, Troya M, Mar Zalduendo M, Orive $G$. The effects of different drugs on the preparation and biological outcomes of plasma rich in growth factors. Annals of Anatomy, 2014;196(6):423-9. https://doi.org/10.1016/j.aanat.2014.06.002 PMid:25053348

22. Sánchez M, Anitua E, Delgado D, Sanchez P, Orive G, Padilla S. Muscle repair: platelet-rich plasma derivates as a bridge from spontaneity to intervention. International Journal of the Care of the Injured, 2014;45:7-14. https://doi.org/10.1016/S0020-1383(14)70004-X

23. Anitua E, Pino A, Troya $M$, Jaén $P$, Orive $G$. A novel personalized 3D injectable protein scaffold for regenerative medicine. Journal of Materials Science: Materials in Medicine, 2017;29(1):7-15. https://doi.org/10.1007/s10856017-6012-6 PMid:29243192

24. Anitua $E$, Pino A, Jaén $P$, Orive $G$. Plasma rich in growth factors improves wound healing and protects against photo-oxidative stress in dermal fibroblasts and 3D skin models. Current Pharmaceutical Biotechnology, 2016;17(6):556-70. https://doi.org/10.2174/1389201017666160301104139 PMid:26927211

25. Anitua E, Pino A, Martinez N, Orive G, Berridi D. The effect of plasma rich in growth factors on pattern hair loss: a pilot study. Dermatologic Surgery, 2017;43(5):658-70. https://doi.org/10.1097/DSS.0000000000001049 PMid:28221183 
26. Bayer A, Tohidnedzhad M, Berndt R, Lippross S, Behrendt P, Klüter T, Pufe T, Jahr H, Cremer J, Rademacher, Maren Simanski F, Gläser R, Harder J. Platelet-released growth factors inhibit proliferation of primary keratinocytes invitro. Annals of Anatomy - Anatomischer Anzeiger, 2018;215:1-7. https://doi.org/10.1016/j.aanat.2017.09.002 PMid:28931468

27. Elghblawi E. Platelet-rich plasma, the ultimate secret for youthful skin elixir and hair growth triggering. Journal of Cosmetic Dermatology, 2018;17(3):423-30. https://doi.org/10.1111/jocd.12404 PMid:28887865

\section{$\diamond \diamond \diamond \diamond \diamond \diamond \diamond$}

http://www.ejgm.co.uk 